\title{
Influence of thermo-mechanical treatments on the microstructure and hardness of the Al-2024 alloy
}

\author{
C.G. Garay-Reyes, L. González-Rodelas, E. Cuadros-Lugo, I. Estrada-Guel and R. Martínez-Sánchez \\ Centro de Investigación en Materiales Avanzados (CIMAV) Miguel de Cervantes No. 120, 31109, \\ Chihuahua, Chih., México.
}

The Al-2024 alloy as a heat-treatable material, exhibits certain excellent properties, such as high tensile strength, good damage tolerance and creep resistance. With the excellent thermal stability, these alloys are considered to be candidate materials for future applications in the aerospace industry [1]. Actually, recent demand for weight reduction in structural component calls for further enhancement of strength of commercial structural alloys. Increasing recognition has been given to the thermos-mechanical treatments recently as important techniques for improving the properties of metallic materials [2]. The plastic deformation process may be useful in the effect of aging process and helpful to improve the mechanical properties of Al-2024 alloy. Some studies have shown that the plastic deformation process may be useful in the effect of aging process, which is helpful to improve the mechanical properties of aluminum alloy and refine the precipitated phase of alloys notably [3]. However, there are few studies available concerning the effect of the pre-deformation degree on the microstructure and precipitation kinetics.

The Al-2024 alloy was melted in a LINDBERG BLUE electric furnace at $740^{\circ} \mathrm{C}$, degassed for 5 minutes with Argon gas (20 psi), using a graphite propeller at $490 \mathrm{rpm}$ and finally $0.33 \mathrm{wt} \%$ of $\mathrm{Al}-5 \mathrm{Ti}-1 \mathrm{~B}$ as grain refiner was added. The alloys were cast into steel molds preheated at $260^{\circ} \mathrm{C}$, where specimens of approximately $101.39 \mathrm{~mm}$ long x $12.64 \mathrm{~mm}$ wide $\times 9.57 \mathrm{~mm}$ height were obtained. Later these specimens were machined to obtain samples of approximately $97 \mathrm{~mm}$ long x $10 \mathrm{~mm}$ wide x 8mm high. Subsequently, hot rolling (pre-deformation) at $\approx 460{ }^{\circ} \mathrm{C}$ was carried out to reduce the thickness of the sample $50 \%$ and erase the as-cast microstructure. Subsequently, solution treatments at $495^{\circ} \mathrm{C}$ for 3,5 and $7 \mathrm{~h}$ were done in a LINDBERG-BLUE electric furnace followed by a quenching in water at $60^{\circ} \mathrm{C}$. Thereafter, a cold rolling was carried out to reduce the thickness of the sample 5 and $15 \%$. Finally, samples were cut approximately $19.46 \mathrm{~mm}$ long to be treated by aging in a FELISA furnace at $195^{\circ} \mathrm{C}$ for different periods of time. The microstructural evolution was studied by optical microscopy (OM), scanning electron microscopy (SEM) and transmission electron microscopy (TEM).

The effect of homogenization-solubilization treatment time (3, 5 and $7 \mathrm{~h}$ ) on microstructure in Al-2024 alloy is shown by SEM micrographs in Fig. 1. It is observed from the results that in all homogenizationsolubilization treatment times, segregation decrease compared with as-cast conditions, but samples treated for 5 and 7 h shown lower segregation.

The Fig. 2 shows HRB and HV harness results as a function of aging time in the 2024 alloy, after 5 (a) and $15 \%$ (b) cold-working, additionally, the reference sample value is included. It is observed as the hardness in cold-working samples is greater than the reference samples. It is observed a direct effect of cold-working in hardness, high deformation - high hardness. Additionally, the cold-working affects the precipitation kinetics; it is observed that the time required to reach peak hardness in deformed samples is shorter than that observed in not deformed samples, it is expected a noticeable effect on the morphology, 
size and distribution of precipitates. In addition, the precipitation kinetics is faster in the samples $15 \%$ cold-working compared to 5\% cold-working and reference sample, which is in agree with reported in other studies [5].

\section{References}

[1]S.K. Ghosh, J Mater Sci Technol 27 (2011), p. 193-198.

[2] AL Ning, ZY Liu, SM Zeng, Trans Nonferr Met Soc China 16 (2006), p. 1341-1347.

[3] Hengcheng Liao et al, JMEPEG 20 (2011), p. 1364-1369.

[4] Zhanli Guo, Wei Sha, Mater Trans 43 (2002), p. 1273-1282.

[5] Xiaofeng Xu et al, J Alloy Compd 610 (2014), p. 506-510.
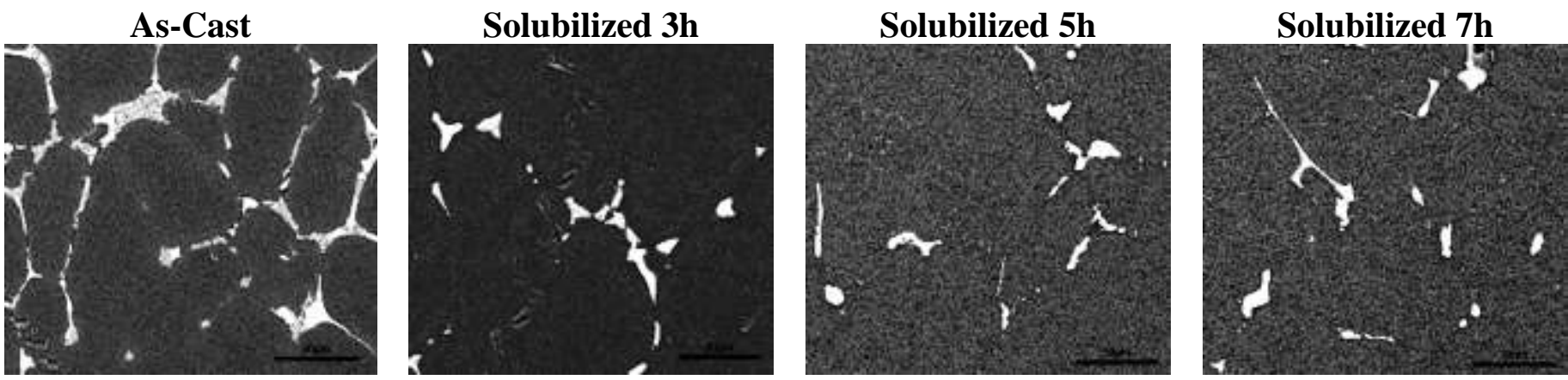

Figure. 1Images obtained by SEM in Al-2024 alloy as function of homogenization-solution treatment time.
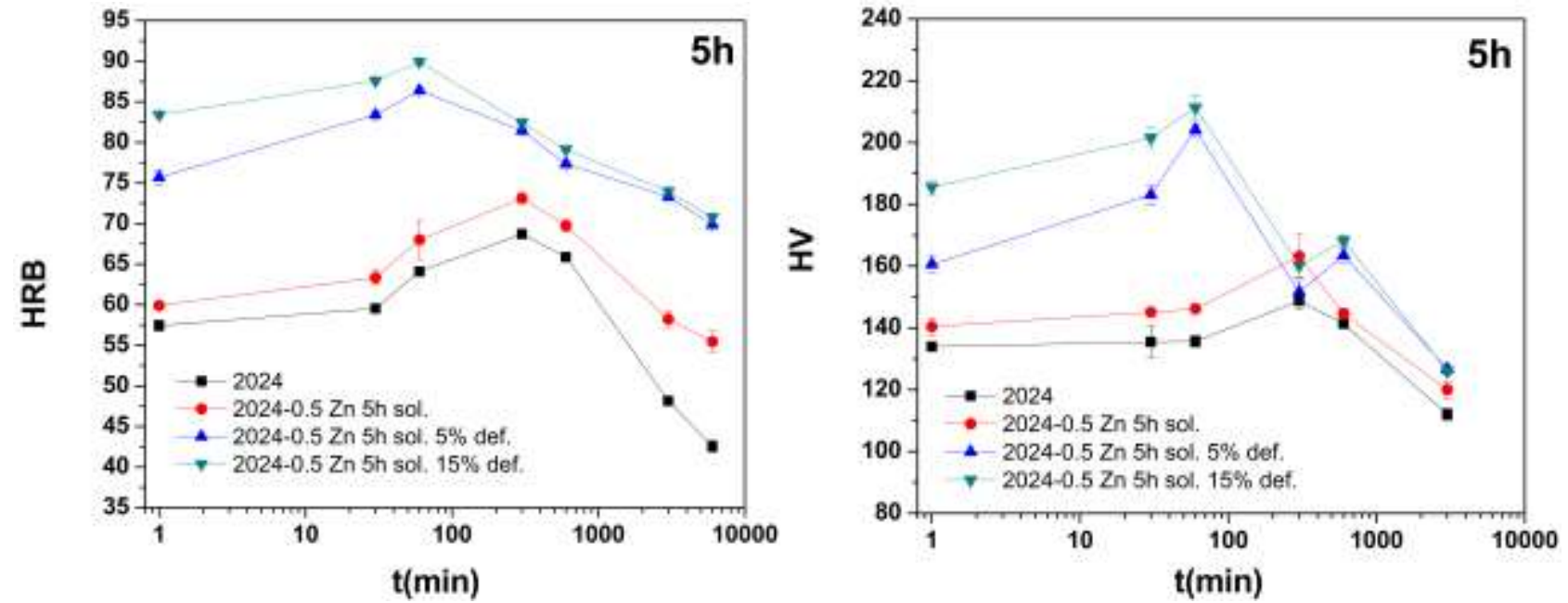

Figure. 2 Hardness HRB and HV curves as a function of aging in Al-2024 alloy solubilized for 5h . Hardness of $5 \%$ and $15 \%$ cold-working and reference samples are shown. 